\title{
Improvement of Library Satisfaction Based on Fuzzy MICMAC Modified IPA Method
}

\author{
Jintao Lee and Jihkuang Chen ${ }^{\text {a, * }}$ \\ Xiamen University Tan Kah Kee College, Zhangzhou 363105, China \\ *,apony1146@163.com
}

Keywords: IPA, MICMAC, Modified IPA.

\begin{abstract}
This study proposed the novel integration of Fuzzy MICMAC and IPA model to make effective explore and analysis the service quality improvement of library. Thru a case study of Xiamen University Tan Kah Kee College library to verify the availability and effectiveness of this approach, in addition, some management and improvement strategies are also obtained.
\end{abstract}

\section{Introduction}

Library's readership satisfaction evaluation is an important means to improve library management. Past research has focused on the use of the LibQUAL model developed from SERVQUAL [1]; and the structural equation model to explore the impact of each of these variables [2]. However, there are few literatures about the optimization strategy. Thus, a few researches use the importance-performance analysis (IPA) to explore the optimization strategy of satisfaction [3]. Importance Performance Analysis (IPA) proposed by Martilla and James (1977) [4] is one of the methods widely used and has attracted the interest of various academics and practitioners from different fields (Feng et al., 2014) [5].

However, many scholars have put forward some shortcomings of IPA, as well as some methods to improve it. Such as Lee et al. (2008) [6] firstly proposed Integrating a complex problem analysis technique-Decision Making Trial and Evaluation Laboratory (DEMATEL) for the management strategy of including the degree of interaction between the attribute to amend the IPA. But basically, the concept of Lee et al. still be used, with attributes' distributed situation and placement in quadrant of IPA grid and the DEMATEL grid, to sum up the direction of an integrated judgment, but there was not a more quantitative integration method, the application was inconvenient. Therefore, this study adopts the novel integration of Fuzzy MICMAC and IPA model to make effective explore and analysis. In addition to verifying the availability and effectiveness of this approach, some management and improvement strategies are also obtained.

\section{Methodology}

\subsection{Fuzzy MICMAC.}

The adjacency matrix of MICMAC is from binary evaluation, it is easy to cause the deviation of the evaluation result, thus, Fuzzy theory is integrated, which can improve this shortcoming. In this study, the triangular fuzzy number is used to divide the impact of attribute into 5 grades: "No influence"; "Slight influence"; "Middle influence"; "Larger influence" and "Strong influence", which can be expressed as $11,12,13,14,15$, therefore, the linguistic function can be expressed as: $F(1 i)={ }^{\tilde{l}}, \mathrm{i}=0$, $0.25,0.5,0.75,1$ in which $^{\hat{\imath}}$ is a fuzzy number. The following methods can be used to integrate the multiple decisions making result:

$$
A_{i j}=\min \left\{e_{i j p}\right\}, B_{i j}=\left[\Pi_{p}^{n} e_{i j p}\right]^{1 / n}, C_{i j}=\max \left\{e_{i j p}\right\}
$$

$\mathrm{e}_{\mathrm{ijp}}$ is ordered to be the valuation matrix, being used to express the decision value of attribute in item $i$ and $j$ of digit $p$. The integrated fuzzy number is ordered to be $\widetilde{A_{1 j}}=\left(A_{i j}, B_{i j}, C_{i j}\right)$, then, defuzzify 
by using the graded mean method to calculate the property average (PA) to be real number. Formula is as shown as formula (2):

$$
P A_{i j}=\frac{\left(A_{i j}+4 B_{i j}+C_{i j}\right)}{6}
$$

At last, compare each property average with the central fuzzy number 0.5 , which >central fuzzy number as 1 , and <central fuzzy number as 0 . Finally, the results can be converted into the adjacency matrix.

\subsection{Integrated with IPA.}

Based on the steps of Fuzzy-MICMAC, degree of influence between attribute is analyzed untill getting reachability matrix, and the Influence (D-value) and Dependence (R-value) of each attribute are calculated. Then according to influence and dependence of attribute, D-value coefficient (CoD) and R-value coefficient (CoR) are calculated. The reason for this coefficient is that D-value represents the total impact of the attribute on other attribute. R-value is the total dependency of the attribute on other attributes. Thus, when the total impact of attribute is greater than the total dependence, represents that the importance of the attribute should be greater. On the contrary, when the total dependence of the attribute is greater than the total impact, the performance value of the attribute is too high, the specific formulas is as follows:

D-value coefficient $(\mathrm{CoD})$ :

$$
\operatorname{CoD}_{i}=1+\left(D_{i}-R_{i}\right) /\left(D_{i}+R_{i}\right), \text { while Di }>\text { Ri }
$$

R-value coefficient $(\mathrm{CoR})$ :

$$
C_{0 R}=1-\left|\left(D_{i}-R_{i}\right) /\left(D_{i}+R_{i}\right)\right|, \text { while Di }<\mathrm{Ri}
$$

Finally, the adjusted coefficients are used to modify the importance and performance from conventional IPA method. When the influence degree of an attribute is equal to the dependent degree, it is not necessary to modify it. When the influence degree of a attribute is greater than the dependent degree, the revised importance (RI) is calculated by formula (5); and when the influence degree of a attribute is less than the dependent degree, the revised (performance) (RP) is calculated by formula (6).

The revised Importance (RI):

The revised performance $(\mathrm{RP})$ :

$$
R I_{i}=I_{i} \times C o D_{i}
$$

$$
R P_{\mathrm{i}}=P_{\mathrm{i}} \times \mathrm{CoR}_{\mathrm{i}}
$$

Finally, the RI and RP of attribute are used to draw IPA grid, and according to it for the analysis of management decisions.

\section{Case Study}

\subsection{Determine the Service Quality Elements and Summary of Expert Opinion.}

This study adopts the latest version of LibQUAL + 2010 and references the past studies, respectively, visited five teachers of TKK College, screening and correction of these elements, obtain the final 20 items of evaluation of service quality and satisfaction of Xiamen University TKK Library (as shown in Table 1). 
Table 1. Evaluation elements

\begin{tabular}{ccl}
\hline Dimension & Code & \\
\hline \multirow{2}{*}{ Food } & $\mathrm{S}_{1}$ & There are local features of the dishes \\
& $\mathrm{S}_{2}$ & A complete variety of dishes \\
Transportation & $\mathrm{S}_{3}$ & Convenience of public transportation such as subway and bus to reach the scenic spot \\
& $\mathrm{S}_{4}$ & The amount of parking lots \\
& $\mathrm{S}_{5}$ & Parking fee is reasonable \\
& $\mathrm{S}_{6}$ & Reasonable and smooth design of road \\
& $\mathrm{S}_{7}$ & Prominent position, and moderate scale \\
& $\mathrm{S}_{8}$ & The number of guide signs is sufficient and the layout is reasonable \\
& $\mathrm{S}_{9}$ & Ticket price is reasonable \\
& $\mathrm{S}_{10}$ & The way of ticket purchase is convenient \\
& $\mathrm{S}_{11}$ & Layout of the public rest facilities is reasonable and the number is sufficient \\
& $\mathrm{S}_{12}$ & The public toilet is enough and convenient to reach \\
& $\mathrm{S}_{13}$ & The amount of trash is enough and convenient to find \\
& $\mathrm{S}_{14}$ & The fire safety facilities are perfect \\
& $\mathrm{S}_{15}$ & Clean environment \\
& $\mathrm{S}_{16}$ & Polite and friendly service attitude of staff \\
& $\mathrm{S}_{17}$ & Tourism commodities are rich in variety and distinctive in feature \\
& $\mathrm{S}_{18}$ & Reasonable price of tourist commodities \\
Shopping & $\mathrm{S}_{19}$ & The entertainment project is rich in variety and distinctive in feature \\
& $\mathrm{S}_{20}$ & It is very participatory and suitable for all kinds of people \\
\hline
\end{tabular}

\subsection{Integrated Analysis of Fuzzy MICMAC and IPA.}

On the basis of the questionnaire, five experts on library and management were re-visited, who were asked to judge the degree of influence and dependence among the factors respectively. After summarizing five experts' questionnaires, we use fuzzy algorithm to calculate the result of judgment, and finally compare the judgment of the pasting with the central value and get the adjacency matrix.

The addition of the adjacency matrix $A$ and the unit matrix I is added to get the element association matrix N. The operations of the Boolean algebra of matrix until convergence of $\mathrm{N} 2=\mathrm{N} 3=\mathrm{N} 4$ obtains the reachability matrix $(\mathrm{M})$. The influence and dependence of the elements are calculated. Then, according to the influence and dependence of each element, the importance adjustment coefficient $(\mathrm{CoI})$ and the performance adjustment coefficient $(\mathrm{CoP})$ are calculated. At last, the correction formula of (5) and (6) is used to adjust the importance and performance of the traditional IPA method. The results are shown in Table 2.

Table 2. Revised importance (RI) and correction performance (RP)

\begin{tabular}{ccccccc}
\hline Code & Performance & CoP & RP & Importance & CoI & RI \\
\hline $\mathrm{S}_{1}$ & 3.48 & 1 & 3.48 & 3.54 & 1 & 3.54 \\
$\mathrm{~S}_{2}$ & 3.51 & 1 & 3.51 & 3.52 & 1 & 3.52 \\
$\mathrm{~S}_{3}$ & 3.83 & 1 & 3.83 & 4.3 & 1 & 4.3 \\
$\mathrm{~S}_{4}$ & 3.63 & 1 & 3.63 & 3.66 & 1 & 3.66 \\
$\mathrm{~S}_{5}$ & 3.36 & 1 & 3.36 & 3.51 & 1 & 3.51 \\
$\mathrm{~S}_{6}$ & 3.72 & 4.31 & 3.72 & 3.59 & 1 & 4.31 \\
$\mathrm{~S}_{7}$ & 4.42 & 1 & 2.21 & 3.45 & 2.21 & 3.45 \\
$\mathrm{~S}_{8}$ & 3.84 & 5.46 & 3.84 & 3.12 & 1 & 5.46 \\
$\mathrm{~S}_{9}$ & 3.09 & 1 & 3.09 & 4.21 & 1 & 4.21 \\
$\mathrm{~S}_{10}$ & 3.71 & 1 & 3.71 & 3.89 & 1 & 3.78 \\
$\mathrm{~S}_{11}$ & 3.76 & 1 & 1.88 & 3.94 & 1.88 & 3.94 \\
$\mathrm{~S}_{12}$ & 3.86 & 1 & 2.57 & 4.32 & 2.57 & 4.32 \\
$\mathrm{~S}_{13}$ & 4.03 & 1 & 2.69 & 4.3 & 2.69 & 4.3 \\
$\mathrm{~S}_{14}$ & 3.88 & 1 & 2.59 & 3.77 & 2.59 & 3.77 \\
$\mathrm{~S}_{15}$ & 3.78 & 1 & 3.78 & 4.21 & 1 & 4.21 \\
$\mathrm{~S}_{16}$ & 3.9 & 5.45 & 3.9 & 3.63 & 1 & 5.45 \\
$\mathrm{~S}_{17}$ & 3.64 & 1 & 2.43 & 3.49 & 2.43 & 3.49 \\
$\mathrm{~S}_{18}$ & 3.32 & 4.32 & 3.32 & 3.24 & 1 & 4.32 \\
$\mathrm{~S}_{19}$ & 5.83 & 1 & 2.92 & 4.39 & 2.92 & 4.39 \\
$\mathrm{~S}_{20}$ & 3.6 & 1 & 3.6 & 4.21 & 1 & 4.21 \\
\hline
\end{tabular}




\subsection{Drawing Importance - Performance Two-Dimensional Graph.}

As shown in Table 5, the correction importance and correction performance are drawn and the IPA importance - Performance two-dimensional matrix diagram is drawn, as shown in Figure 1.

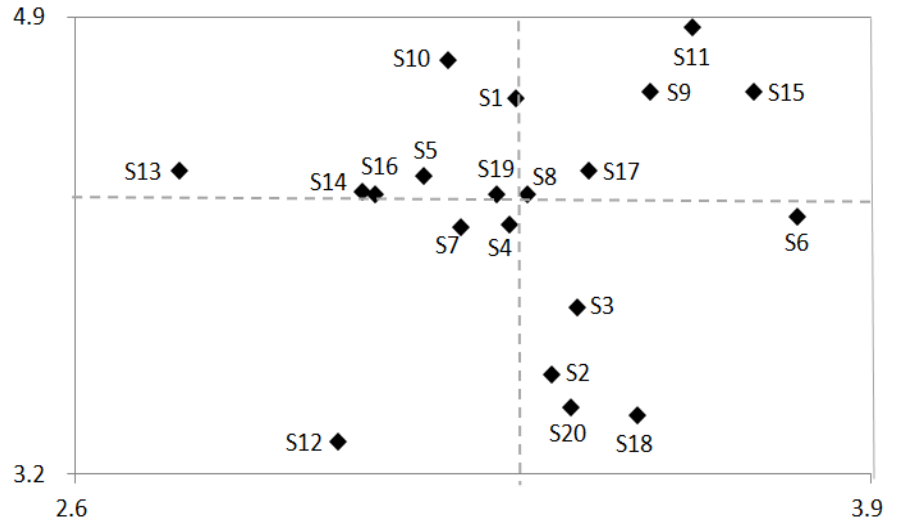

Figure 1. new IPA importance degree - Performance two-dimensional matrix diagram

\subsection{Result}

According to the IPA and Fuzzy MICMAC integration method, the result obtained is that there are five elements S8, S9, S11, S15 and S17 within the quadrant one. In quadrant II there are seven elements S1, S5, S10, S13, S14, S16 and S19. There are three elements S4, S7 and S12 in quadrant III. There are five elements S2, S3, S6, S18 and S20 in Quadrant IV. From this we can get the library optimization strategy, priority should be given to improve the seven elements of quadrant II, and maintain the five elements of quadrant I.

\section{Conclusion}

This study proposes Fuzzy MICMAC method to calculate and analyze the influence and dependence among elements. The main contributions and innovations is a quantitative formula proposed, thus making comprehensive judgment according to the influence and dependence of attribute, and amend properly the importance or performance of element, then the gained revised importance and revised performance are used for IPA grid, then make management decision making and resource allocation according to it. However, the limitations of this study may be the insufficient accuracy caused by insufficient number of invited experts, or lack of representation when making judgment of influence and dependence among attributes. It shall be verified by subsequent empirical studies.

\section{References}

[1] Bai L N, Lu P, Qiao A L. The empirical study on Library Service quality based on LibQUAL+ ${ }^{\mathrm{TM}}$ : a case study of Harbin Engineering University Library. Library Journal. Vol.33(2014) No. 9, p. 60-65.

[2] Lu Z P, Su W C. An empirical study on the quality and satisfaction of Cultural Service in Public Libraries. Library Forum. Vol.36(2015) No. 9, p. 67-76.

[3] Wang Y. Evaluation of Library Reader satisfaction based on IPA Model-A case study of Hubei Library. Shanxi Library Journal. Vol.11(2013) No.2, p. 57-60.

[4] Martilla J A, James J C. Importance-Performance analysis. Journal of Markeing. Vol.41(1977) No. 1, p. 77-79.

[5] Feng M, Mangan J, Wong C. Investigating the different approaches to importance-performance analysis. The Service Industries Journal, Vol.34(2014) No.12, p. 1021-1041.

[6] Lee Y C, Yen T M, Tsai C H. Using importance-performance analysis and decision-making trial and evaluation laboratory to enhance order-winner criteria: A study of computer industry. Information Technology Journal, Vol. 16(2008) No.7, p. 396-408. 